\title{
A Comparison between Li-Fi, Wi-Fi, and Ethernet Standards
}

\author{
Wafa S. M. Elbasher ${ }^{1}$, Amin B. A. Mustafa ${ }^{2}$, Ashraf A. Osman ${ }^{3}$ \\ ${ }^{1}$ Faculty of Engineering, Al- Neelain University, Khartoum, Sudan \\ ${ }^{2}$ Faculty of Engineering, Al- Neelain University, Khartoum, Sudan, \\ ${ }^{3}$ Staff Computer Design Engineer, Folsom, CA, USA
}

\begin{abstract}
The LiFi, WiFi, and Ethernet technologies form three types of high frequency technologies for communication networks. The WiFi and Ethernet use the radio frequency waves for communications, while the LiFi technology uses light as medium of communications. Hence, the LiFi frequency band are in the Tera $\mathrm{Hz}$ range compared to $\mathrm{GHz}$ of WiFi and Ethernet. The Li-Fi solves bandwidth issues, and they are suitable for confined space communications. The vast presence of light sources in today's world offer great opportunity to utilize such technology for communications. Several location can be prime for its use such as banks, hospitals, buildings, etc... Inspite these benefits, LiFi still suffers from multiple issues such as interference from various light sources, service interruptions by opaque surfaces, and high implementation costs. The Ethernet technology is known to be high reliability technique, but lacks mobility and flexibility. It is imperative to investigate each technology application areas and features to help design better communication networks.
\end{abstract}

Keywords: IEEE802.11, networking, communications, WiFi, LiFi, Ethernet

\section{Introduction}

There has been a drastic change in how mobile communication devices are being used with data transfer and with mobility scenarios. Mobile users have been trafficking more data than voice while using these mobile devices leading to change of communication environment. According to [1], the number of mobile devices subscription outlook during 2014 - 2020 will be as shown in Table 1.

Table 1: Mobile subscription outlook as stated by [1]

\begin{tabular}{|c|c|c|}
\hline Subscriptions & 2014 & 2020 \\
\hline Total mobile & 7.1 billion & 9.2 billion \\
\hline Mobile broadband & 2.9 billion & 7.7 billion \\
\hline Smartphones & 2.6 billion & 6.1 billion \\
\hline Mobile PCs, tablets and routers & 250 million & 400 million \\
\hline
\end{tabular}

From Table 1, the vast number of mobile devices as well as the rapid growth of subscribers are evident. Also, it worth noting that the mobile PCs, tablets, and routers growth is much slower than mobile broadband devices and smart phones. To support the aforementioned growth, new connectivity technologies have emerged in the communication market. These include the LiFi, WiFi, and Ethernet technologies which follow various standards on how systems are built and how they communicate. The features list and differences between the LiFi and WiFi technologies are listed in Table 2. These three technologies are focused on high speed communications and would be interesting to compare these techniques against each other.

In this article, the technology specifications of $\mathrm{LiFi}, \mathrm{WiFi}$, and Ethernet systems will be discussed. A comparative study of QoS of the three systems will be tabulated and conclusions will be drawn.

Table 2: Basic differences between LiFi and WiFi standards

\begin{tabular}{|c|c|c|}
\hline Feature & $\mathrm{LiFi}$ & WiFi \\
\hline Full form & Light Fidelity & Wireless Fidelity \\
\hline Operation & $\begin{array}{l}\text { LiFi transmits data using light with the help of LED } \\
\text { bulbs. }\end{array}$ & $\begin{array}{l}\text { WiFi transmits data using radio waves with the help of } \\
\text { WiFi router. }\end{array}$ \\
\hline Interference & $\begin{array}{c}\text { Do not have any interference issues similar to radio } \\
\text { frequency waves. }\end{array}$ & $\begin{array}{c}\text { Will have interference issues from nearby access points } \\
\text { (routers) }\end{array}$ \\
\hline Technology & Present IrDA compliant devices & WLAN $802.11 \mathrm{a} / \mathrm{b} / \mathrm{g} / \mathrm{n} / \mathrm{ac} / \mathrm{ad}$ standard compliant devices \\
\hline Applications & $\begin{array}{l}\text { Used in airlines, undersea explorations, operation } \\
\text { theaters in the hospitals, office and home premises for } \\
\text { data transfer and internet browsing }\end{array}$ & $\begin{array}{l}\text { Used for internet browsing with the help of WiFi kiosks or } \\
\text { hotspots }\end{array}$ \\
\hline Advantages & $\begin{array}{c}\text { Interference is less, can pass through salty sea water, } \\
\text { works in dense region }\end{array}$ & $\begin{array}{c}\text { Prone to interference, can't pass through sea water, works } \\
\text { in less dense region }\end{array}$ \\
\hline Privacy & $\begin{array}{c}\text { light is blocked by the walls, therefor more secured on } \\
\text { data transfer }\end{array}$ & $\begin{array}{c}\text { For RF signal, dry walls are transparent, therefore need to } \\
\text { employ techniques to achieve secure data transfer. }\end{array}$ \\
\hline $\begin{array}{c}\text { Data transfer } \\
\text { speed }\end{array}$ & About 1 Gbps & $\begin{array}{l}\text { WLAN-11n offers 150Mbps, About 1-2 Gbps can be } \\
\text { achieved using WiGig/Giga-IR }\end{array}$ \\
\hline $\begin{array}{c}\text { Frequency of } \\
\text { operation }\end{array}$ & $\begin{array}{c}10,000 \text { times frequency spectrum of the radio (In the } \\
\text { Tera Hz range) }\end{array}$ & $2.4 \mathrm{GHz}, 4.9 \mathrm{GHz}$ and $5 \mathrm{GHz}$ \\
\hline
\end{tabular}




\section{International Journal of Science and Research (IJSR) \\ ISSN (Online): 2319-7064}

Index Copernicus Value (2013): 6.14 | Impact Factor (2014): 5.611

\begin{tabular}{|c|c|c|} 
Data density & Works in high dense environment & $\begin{array}{c}\text { Works in less dense environment due to interference } \\
\text { related issues }\end{array}$ \\
\hline $\begin{array}{c}\text { Coverage } \\
\text { distance }\end{array}$ & About 10 meters & $\begin{array}{c}\text { About 32 meters (WLAN 802.11b/11g), vary based on } \\
\text { transmit power and antenna type }\end{array}$ \\
\hline $\begin{array}{c}\text { System } \\
\text { components }\end{array}$ & $\begin{array}{c}\text { Lamp driver, LED bulb (lamp) and photo detector will } \\
\text { make up complete LiFi system. }\end{array}$ & $\begin{array}{c}\text { requires routers to be installed, subscriber devices (laptops, } \\
\text { PDAs, desktops) are referred as stations }\end{array}$ \\
\hline
\end{tabular}

\section{LiFi, WiFi, and Ethernet Technology Details}

\section{A. Ethernet}

The Ethernet standards is a well-established technology that was released commercially during 1980 as the IEEE802.3. It has been a relatively inexpensive, reasonably fast, and very popular LAN technology for several decades [2]. The most commonly installed Ethernet systems are called 10BASE-T and provide transmission speeds up to $10 \mathrm{Mbps}$. Ethernet data transfer rates have been increased from the original 2.94( Mbit/s) to the latest $100(\mathrm{Gbit} / \mathrm{s})$. Jorg Sommer et. al. [3] have investigated fields of Ethernet applications and found them concentrated on three major categories:

- The operated and managed networks of carriers in the core and access part of a public or private network;

- The embedded networks in the manufacturing environment, in aircraft, and in cars;
- The home entertainment (AVB) networks residing between LAN and category two.

Please refer to Table 3. For more relevant details on Ethernet technologies and a comparison with other technologies.

\section{B. WiFi}

WiFi - is a short name for Wireless Fidelity, and this system was released during 1990 with standard IEEE 802.11. This technology was designed to provide wireless connectivity to devices that require a quick installation, such as portable computers PDAs or generally mobile devices inside a WLAN network [4]. Table 3 provide more insight to the IEEE802.11 various components specifications.

Table 3: Comparison Between IEEE 802.11 Standards [5]

\begin{tabular}{|c|c|c|c|c|c|c|c|c|}
\hline \multicolumn{9}{|c|}{ 802.11 network PHY standards } \\
\hline \multirow[t]{3}{*}{$\begin{array}{l}802.11 \\
\text { protocol }\end{array}$} & \multirow[t]{3}{*}{$\begin{array}{l}\text { Release } \\
\text { date }\end{array}$} & \multirow[t]{2}{*}{ Frequency } & \multirow[t]{2}{*}{$\begin{array}{l}\text { Band- } \\
\text { width }\end{array}$} & \multirow[t]{2}{*}{$\begin{array}{l}\text { Stream } \\
\text { Data Rate }\end{array}$} & \multirow{3}{*}{\begin{tabular}{|l} 
Allowable \\
MIMO \\
streams
\end{tabular}} & \multirow[t]{3}{*}{$\begin{array}{l}\text { Modulation } \\
\text { Antenna Tech. }\end{array}$} & \multicolumn{2}{|c|}{$\begin{array}{l}\text { Approx. } \\
\text { range }\end{array}$} \\
\hline & & & & & & & In & Out \\
\hline & & $(\mathbf{G H z})$ & $(\mathrm{MHz})$ & $\begin{array}{l}\text { Min-Max } \\
(\text { Mbit/s) }\end{array}$ & & & (m) & $(\mathbf{m})$ \\
\hline 802.11 & Jun 1997 & 2.4 & 22 & $1-2$ & 1 & $\begin{array}{l}\text { DSSS, } \\
\text { FHSS }\end{array}$ & 20 & 100 \\
\hline \multirow{2}{*}{$\mathrm{a}$} & \multirow{2}{*}{ Sep 1999} & 5 & \multirow{2}{*}{20} & \multirow{2}{*}{$6-54$} & \multirow{2}{*}{1} & \multirow{2}{*}{$\begin{array}{l}\text { OFDM } \\
\text { (SISO) }\end{array}$} & 35 & 120 \\
\hline & & 3.7 & & & & & - & $5 \mathrm{~K}$ \\
\hline $\mathrm{b}$ & Sep 1999 & 2.4 & 22 & $1-11$ & 1 & $\begin{array}{l}\text { DSSS } \\
\text { (SISO) }\end{array}$ & 35 & 140 \\
\hline g & Jun 2003 & 2.4 & 20 & $6-54$ & 1 & $\begin{array}{l}\text { OFDM, DSSS } \\
\text { (SISO) }\end{array}$ & 38 & 140 \\
\hline \multirow{2}{*}{$\mathrm{n}$} & \multirow{2}{*}{ Oct 2009} & \multirow{2}{*}{$2.4 / 5$} & 20 & $\begin{array}{l}7.2-72.2 \\
(6.5-65)\end{array}$ & \multirow{2}{*}{4} & \multirow{2}{*}{$\begin{array}{l}\text { OFDM } \\
\text { (MIMO) }\end{array}$} & 70 & 250 \\
\hline & & & 40 & $\begin{array}{c}15-150 \\
(13.5-135)\end{array}$ & & & 70 & 250 \\
\hline \multirow{4}{*}{ ac } & \multirow{4}{*}{ Dec 2013} & \multirow{4}{*}{5} & 20 & $\begin{array}{c}7.2-96.3 \\
(6.5-86.7) \\
\end{array}$ & \multirow{4}{*}{8} & \multirow{4}{*}{\begin{tabular}{|l} 
OFDM \\
(MU-MIMO)
\end{tabular}} & 35 & \\
\hline & & & 40 & $\begin{array}{c}15-200 \\
(13.5-180)\end{array}$ & & & 35 & \\
\hline & & & 80 & $\begin{array}{l}32.5-433.3 \\
(29.2-390)\end{array}$ & & & 35 & \\
\hline & & & 160 & $\begin{array}{c}65-866.7 \\
(58.5-780)\end{array}$ & & & 35 & \\
\hline
\end{tabular}

\section{LiFi}

The LiFi considered as a WiFi with light being using light technology instead of Radio waves. It forms a new class of high intensity light source of solid state design bringing clean lighting solutions to general and specialty lighting. With energy efficiency, long useful lifetime, full spectrum and dimming, LiFi lighting applications work better 


\section{International Journal of Science and Research (IJSR) \\ ISSN (Online): 2319-7064 \\ Index Copernicus Value (2013): 6.14 | Impact Factor (2014): 5.611}

compared to conventional approaches. The LiFi provide high efficiency communication system within confined spaces when compared to the WiFi, hence the two technologies can be considered complimentary.

The LiFi system uses standard LED light bulbs which are controlled by a driver that turns the LED on and off, or dims and brightens its light intensity. With Li-Fi enabled LED light bulbs, the driver is used to transmit encoded data by controlling the LED light. An optical sensor is used to

Table 4: Technology Parameters Comparison Between LiFi, WiFi, and the Ethernet Standards

\begin{tabular}{|c|c|c|c|}
\hline Parameters & $\mathbf{L i}-\mathbf{F i}$ & Wi-Fi & Ethernet \\
\hline IEEE Standards & 802.15.17 & $802.11 \mathrm{~b}$ & 802.3 \\
\hline Frequency Band & $100 \mathrm{X}$ Tera $\mathrm{HZ}$ & $2.4 \mathrm{GHZ}$ & \\
\hline Cots & Cheap & Expensive & Medium \\
\hline Data Trans. Medium & Light & Radio Spectrum & UTP-STP- O.F. \\
\hline Network Topology & Point-to-Point & Point-to-Point & Bus-Star \\
\hline Speed & 1-3.5Gbps & 54-250Mbps & 10-1000 Mbps \\
\hline Range & 10 Meters & 20-100 meters & $(100-185)$ meters \\
\hline Security & High & Medium & High \\
\hline Power Energy & Available & less available & Available \\
\hline \multicolumn{4}{|l|}{ QoS } \\
\hline Data rate & & High(low-power models available for battery application & High power over Ethernet \\
\hline Wireless spectrum reliability & & $\begin{array}{c}2.4 \mathrm{GHZ} \\
5 \mathrm{GHZ}\end{array}$ & None \\
\hline Reliability & High & High & Very High \\
\hline Release Date & 2011 & 1990 & 1980 \\
\hline
\end{tabular}

\section{Discussion}

Table 4 illustrates comprehensive comparison between $\mathrm{LiFi}$, $\mathrm{WiFi}$, and the Ethernet technologies. One glaring difference is the operating frequency band for LiFi runs about $100 \mathrm{X}$ WiFi range, i.e. in the Tera $\mathrm{Hz}$ range. The WiFi technology is characterized by its mobility and flexibility besides its acceptable coverage area. However, WiFi is expensive, prone to interference (noisy), and is characterized with low reliability. On the other hand, the Ethernet is an old technology, characterized by its high reliability, low interference and reasonable cost. Nevertheless, the main disadvantages of Ethernet technology is that it does not offer mobility or flexibility.

The LiFi is a new technology that appeared on 2011 and relies on light transmission as medium of communication. It is characterized by low cost, and is more suitable for a pointto-point schemes of operations. The potential benefit of such technology can be great considering that it uses light sources suffers from a set of disadvantageous that can be listed as follows:

- Reliability of operation due to interference from other light sources such as sun light, electrical bulbs, etc ...

- Opaque interfaces blocks communications

- High installation costs

- Receiving devices inability to respond back through light transmission technique.

\section{Conclusions}

A comparison of the $\mathrm{LiFi}, \mathrm{WiFi}$, and Ethernet technologies is presented. The three technologies are high frequency technologies. A list of network parameters are listed for the which are connected in many locations. However, the LiFi receive the data, which is then decoded. This is conceptually similar to Morse code - but at rates of many millions of times a second, which is unperceivable to the human eye. The receiver has optics, and is fast enough to see' the light dimming and brightening, smart enough to decode the Li-Fi data, and then deliver it to the attached device such as a laptop computer. Devices can include both a transmitter and receiver to enjoy two-way communications [6]. technologies to enable tabular comparison format. Wi-Fi facilitate point-to-multiple point connectivity which enable creation of Wi-Fi hotspot zones anywhere. The Li-Fi is solving issues such as shortage of radio frequency bandwidth. Also, the $\mathrm{LiFi}$ is more suitable for reliable communication in confined spaces. The Ethernet technology is known to be high reliability technique, but lacks mobility and flexibility. This study highlight reasonable applications for each type of technology were better performance can be achieved.

\section{References}

[1] Mobile subscriptions outlook, http://www.ericsson.com/res/docs/2015/ericssonmobility-report-june-2015.pdf, Accessed August 22, 2015

[2] Giuseppe Anastasi, Eleonora Borgia, Marco Conti, Enrico Gregori,'IEEE 802.11b Ad Hoc Networks: Performance Measurements", Proceedings of the $23 \mathrm{rd}$ International Conference on Distributed Computing Systems Workshops (ICDCSW'03), 758 - 763, 19-22 May 2003, http://ieeexplore.ieee.org/stamp/stamp.jsp?tp=\&arnumb er $=1203643$

[3] Jorg Sommer, Sebastian Gunreben, Frank Feller, Martin Kohn, Ahlem Mifdaoui, Detlef Saß, and Joachim Scharf, Ethernet - A Survey on its Fields of Application", IEEE COMMUNICATIONS SURVEYS \& TUTORIALS, VOL. 12, NO. 2, SECOND QUARTER 2010, pp 263-284

[4] Gent, G. P., Downing, C., Dalton, J. , "Comparative Performance of Wireless and Powerline LANs for Streaming Media", http://www.researchgate.net/publication/228994046_Co

\section{Volume 4 Issue 12, December 2015}




\section{International Journal of Science and Research (IJSR) \\ ISSN (Online): 2319-7064}

Index Copernicus Value (2013): 6.14 | Impact Factor (2014): 5.611

mparative_Performance_of_Wireless_and_Powerline_L

ANs for Streaming Media

[5] IEEE $80 \overline{2} .11$,

https://en.wikipedia.org/wiki/IEEE_802.11, accessed

November 2, 2015.

[6] White Paper Doc, pureLiFi Ltd. Shedding Light on Li-

Fi”, http://purelifi.com/wp-

content/uploads/2013/09/Shedding-Light-On-LiFi.pdf 